\title{
Modeling the Trustworthiness of a Supplier Agent in a B2B Relationship
}

\author{
Patrícia Alves ${ }^{1}$, Pedro Campos ${ }^{1,2}$, and Eugénio Oliveira ${ }^{3}$ \\ ${ }^{1}$ LIAAD - Laboratório de Inteligência Artificial e Apoio à Decisão - INESC TEC, \\ Porto, Portugal \\ ${ }^{2}$ Faculdade de Economia da Universidade do Porto, Portugal \\ pcampos@fep.up.pt \\ ${ }^{3}$ DEI-LIACC - Faculdade de Engenharia da Universidade do Porto, Portugal \\ \{patricia.alves, eco\} @fe.up.pt
}

\begin{abstract}
In life, trust is considered the base of all relationships, including Business-to-Business (B2B) relationships. The selection of a supplier depends not only on its reputation and the costs involved, but also on its trustworthiness and other factors. But how can the trustworthiness of a supplier be measured? What are the factors that influence the supplier's trustworthiness, i.e., what are the relevant factors of trust in the selection of a supplier in a B2B relationship? Answers to these questions will help model the supplier agents' behavior in the multi-agent ANTE platform. In this paper we propose to consider fifteen attributes to measure the trustworthiness of a supplier as a conceptual model of trust, coming out of a combination of several determinants gathered from the literature review. Raw data was gathered by sending a questionnaire to a set of firms from different industrial sectors. The results support part of the proposed determinants, introducing new determinants of trust that resulted from exploratory factor analysis and a new model obtained from confirmatory factor analysis. With this, two possible multi-attribute supplier agents can be modeled. This paper discusses the results and limitations of this study and proposes suggestions for future work.
\end{abstract}

Keywords: B2B relationships, Trust, Trustworthiness, Trustworthiness determinants/attributes.

\section{Introduction}

To engage on a B2B relationship it is important to know the other party, or the risks involved and vulnerability can be quite high. What can be important for the relationship to work successfully and to both parties be satisfied with the contracts made? These questions arise in the sequence of the multi-agent ANTE $^{1}$ platform described in [1], that works as an Electronic Institution, where interactions between the buyers and suppliers arise, leading to the emergence of collaborative networks. In

\footnotetext{
${ }^{1}$ Agreement Negotiation in Normative and Trust-enabled Environments.
} 
this platform the buyer agents select the best proposals by weighting up the utility associated to each proposal with the trustworthiness of the supplier agent [2]. But what is trustworthiness? How can the trustworthiness of a supplier agent be determined and measured? What are the factors that determine if a supplier is trustworthy or not? These questions led to the need for researching and determining the attributes that can measure the trustworthiness of a supplier and help model the agent's behavior in the system.

Why focus on interorganizational trust? In life, trust is considered the base of all relationships and as Pavlou [3] says, has been associated with successful buyer-supplier relationships $[4,5,6,7,8,9]$ and desirable outcomes such as competitive advantage [4, 9], performance, conflict and opportunism reduction [8, 9], and satisfaction [7, 9], leading to the continuity of the relationship [3]. Furthermore, trusting relationships are likely to have lower transaction costs because incomplete contracts are sufficient for running the exchange relationship [9]. Like Doney et al. [10] say, "trust takes on even greater importance in the arena of B2B services as buyers face the complexity of examining many intangible aspects of a service firm's offering". Thus, undoubtedly trust has an important role in the B2B relationships (interorganizational trust) and therefore, in the selection of the suppliers.

So, what is trust? There is no consensus on an universal definition of trust since the relevant context affects its actual meaning, resulting in a large number of definitions [3, 11]. But like Castelfranchi and Falcone [12] say, all definitions go back to the "same layered notion, used to refer to several different (although interrelated) meanings". Given two individuals $\mathrm{X}$ and $\mathrm{Y}$ : (a) "in its basic sense, trust is just a mental and affective attitude or disposition towards $\mathrm{Y}$ involving two basic types of beliefs: evaluations and expectations"; (b) "in its richer use, trust is a decision and intention based on that disposition"; (c) "as well as the act of relying upon Y's expected behavior"; (d) "and the consequent social relation established between X and Y". Ganesan [9] also supported this definition earlier. Therefore the basic concept of trust is cognitive related. But for interorganizational trust, the cognitive part of trust is not enough. Considering $\mathrm{X}$ the buyer, $\mathrm{X}$ cannot just rely upon his beliefs ${ }^{2}$ on $\mathrm{Y}$ (the supplier) to make a transaction, which would be very naïve and risky. Thus, some characteristics of $\mathrm{Y}$ need to be known by X, so he can say that he trusts Y, i.e., that Y is trustworthy. So, we decided to find these characteristics and engage on a quest for the determinants of the trustworthiness of a supplier in B2B relationship, so the computational agent, whose role is a supplier, can be modeled in the multi-agent system more accurately, providing better and more solid contracts and transactions, making the system more realistic. Exploratory and Confirmatory Factor Analysis (EFA and CFA, respectively) were used in order to confirm the adequacy of the conceptual model of trust.

The rest of this paper is organized as follows: the next section provides a review on the most relevant literature on trust in a $\mathrm{B} 2 \mathrm{~B}$ relationship and describes the proposed

\footnotetext{
${ }^{2}$ Or familiarity, because as stated by [3], "e-commerce brings together a massive number of parties with no familiarity and cultural similarities".
} 
model. Section 3 exposes the research methodology and reports the results. In Section 4 some conclusions and suggestions for future work are taken.

\section{$2 \quad$ Literature Review and Proposed Conceptual Model}

There is a wide variety of papers on trust and in many areas that as far as we can tell, go back to the 1950s [13]: psychology, sociology, economics and marketing, and a lot of research has been made on trust in a B2B relationship. Many of the papers found are of great relevance and many can complement each other giving their contribution for the determinants of trust, but unfortunately, not all can be referenced here. So, only the ones considered more relevant are reviewed in this paper.

In 1994, Ganesan [9] affirmed that so far, researchers in marketing have wrongly treated trust as an unidimensional variable, stating that research in interpersonal trust has shown that trust is a multidimensional variable, identifying two distinct dimensions: credibility and benevolence. "Simply put, the credibility dimension refers to intentions of cooperative behavior that results from making opportunism costly or irrational, while the benevolence dimension is a trust expectation that results from goodwill that firms will not act opportunistically, even given the chance" [3]. Therefore, Ganesan proposed a model suggesting the reputation of the vendor, the retailer's satisfaction with previous outcomes, the retailer's experience with a vendor and the retailer's perception of vendor transaction-specific investments, as the antecedents of trust.

In 1997, Doney and Cannon [6] concluded that the supplier's size, the supplier's willingness to customize and trust on the supplier's salesperson have a positive impact on the buyer's trust, but that the supplier's willingness to share confidential information and length of the relationship are unrelated to the buyer's trust on the supplier.

A year after, Sako and Helper [14] also conducted a study to find the determinants of trust in supplier relations: "The conditions which facilitated the creation and sustenance of trust - and the containing of opportunism - were found to include longterm commitment, information exchange, technical assistance, and customer reputation."

Later in 2002, and according to his revision on several authors, including [6, 9, 14, 15, 16, 17], Pavlou [3] also summarized interorganizational trust in two great dimensions: credibility and benevolence. These two dimensions cannot be measured directly (latent or unobserved variables) and so they depend on other variables that can be measured directly (observed variables, factors or constructs). Therefore, [3] proposes five constructs that can positively influence the trust in the suppliers: perceived monitoring, perceived accreditation, perceived legal bonds, perceived feedback and cooperative norms.

Some years after, in 2005, Gounaris [18] suggests that the degree of trust between the supplier and the buyer is directly influenced by the quality of the service and by the bonding strategy and techniques of the provider. 
So, with all this information and because of limitations in previous works, we decided to propose a different and more complete model that gathers the determinants we considered more important from all the analyzed papers, and that is described next.

\subsection{The Trustworthiness of a Supplier: Conceptual Model}

Considering the reviewed literature, we found that the papers by themselves were somehow incomplete, but that together, they could complement each other, giving a better insight of the possible attributes (or constructs, determinants) for modeling the trustworthiness of a supplier agent. Therefore, we propose the following model, depicted in Figure 1.

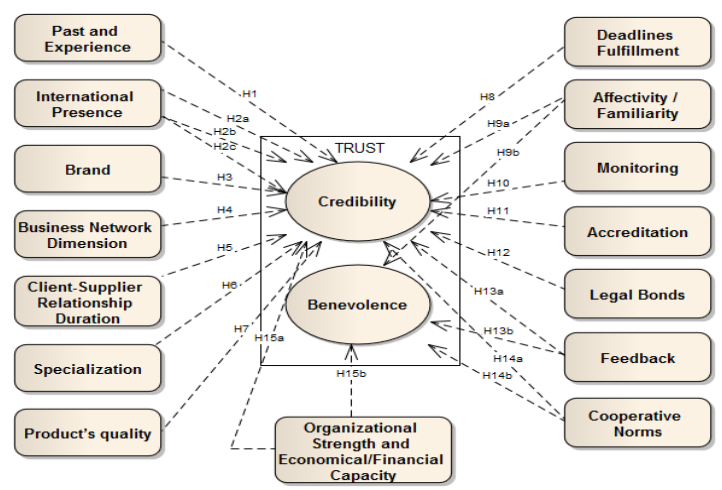

Fig. 1. Determinants of the trustworthiness of a supplier: conceptual model

Next, we shortly describe the proposed attributes and the several hypotheses to be tested in order to verify their impact on trust formation.

Past and Experience (PastExp $X^{\mathbf{3}}$ ). Trustworthiness is related to the supplier's role and behavior at present, and actions it has performed and events it has caused in the past [19], portfolio [20] and prior experience [3, 21]. Formally stated:

H1: Past and experience positively influences the supplier's trustworthiness in terms of credibility.

International Presence (InterX). Sako [14] shows that interorganizational trust varies according to the continent and country. Formally stated:

H2a: The production country of the supplier influences the supplier's trustworthiness in terms of credibility.

${ }^{3}$ Item name, where $\mathrm{X}$ is the number of the corresponding question in the questionnaire (section 3.1). 
H2b: The origin country of the supplier influences the supplier's trustworthiness in terms of credibility.

H2c: The presence of the supplier in several countries positively influences the supplier's trustworthiness in terms of credibility.

Brand (BrandX). Consumers try to reduce risks by using well-known brands, and that brands provide guarantees about quality and security [22, 23, 24]. According to [25], [26] "demonstrate that trust plays an important role in the brand domain in that they link (brand) trust to brand performance through brand loyalty" [27]. Formally stated:

H3: The supplier product's brand positively influences the supplier's trustworthiness in terms of credibility.

Business Network Dimension (DimX). Several enterprises, specially small and medium enterprises, decide to get involved in a larger business network in order to increase their own opportunities of business. This was suggested by several researchers in our research lab, and so, we decided to test if this is an influent factor. Formally stated:

H4: The supplier's business network dimension positively influences the supplier's trustworthiness in terms of credibility.

Buyer-Supplier Relationships Duration (DurX). The historical duration and experience of a relationship is considered of great importance [14, 28]. "Most researchers agree that trust develops and builds over time" [6]. Satisfied buyers stay with the same supplier [25]. Formally stated:

H5: The buyer-supplier relationships duration positively influences the supplier's trustworthiness in terms of credibility.

Specialization (SpecX). The adaptation of the supplier's production processes to meet the buyer's needs and the use of specialized equipment are considered investments in the relationship [6]. Formally stated:

H6: The supplier's specialization positively influences the supplier's trustworthiness in terms of credibility.

Product's Quality (QualityX). The quality of the produced products can be a measure of the suppliers' credibility, since they dedicate more effort in the production of better products to satisfy the buyers and sell more [19]. Formally stated:

H7: The products' quality positively influences the supplier's trustworthiness in terms of credibility.

Deadlines Fulfillment (DFullX). A higher trustworthiness is associated to all the suppliers that were capable of increasing the deliveries frequency without additional costs [14]. It is also important to know when the product will be delivered [20], and [19] propose the adherence to delivery dates to evaluate trust. Formally stated: 
H8: The deadlines fulfillment positively influences the supplier's trustworthiness in terms of credibility.

Affectivity/Familiarity (AfectX). Familiarity and repeated interaction create trust [3, 29, $30,31]$. Zucker [21] argues that trust generated through familiarity and prior experience is probably the most important way of building trust. Formally stated:

H9a: Familiarity with the supplier positively influences the supplier's trustworthiness in terms of benevolence.

H9b: Affectivity towards the supplier positively influences the supplier's trustworthiness in terms of benevolence.

Monitoring (MonitX). According to [3, 19, 32], monitoring encourages responsible behaviors, and is used to confirm if the transactions are taken according to the quality, delivery and performance standards. Formally stated:

H10: Monitoring processes positively influences the supplier's trustworthiness in terms of credibility.

Accreditation (AccreditX). When carried out by an independent authority, accreditation can be a reliable way of assessing the competence of an organization [3]. Formally stated:

H11: Supplier's accreditation positively influences the supplier's trustworthiness in terms of credibility.

Legal Bonds (VinculX). Legal bonds are defined as legitimate contracts that manage the economical activity and have been widely proposed as a mechanism to reduce opportunism and promote trust $[3,14]$. Formally stated:

H12: Legal bonds positively influence the supplier's trustworthiness in terms of credibility.

Feedback $(\boldsymbol{F} \boldsymbol{b} \boldsymbol{X})$. Feedback mechanisms collect and disseminate information about the organizations behavior in past transactions [3], and have been represented as structural assurances that discourage opportunism and engender credibility in online marketplaces [33], providing a signal of good reputation [34], and information about the suppliers' "values, principles and signs of benevolent intentions through buyers' feedback comments" [20,35]. Formally stated:

H13a: Feedback positively influences the supplier's trustworthiness in terms of credibility.

H13b: Feedback positively influences the supplier's trustworthiness in terms of benevolence.

Cooperative Norms (CoopX). "Cooperative norms are defined as values, standards and principles to which a population of organizations adheres" [3]. Values and norms discourage opportunism, facilitate cooperation, promote joint problem solving $[19,36]$ and reduce costs and innovate production and management methods [14]. Formally stated: 
H14a: Cooperative norms positively influence the supplier's trustworthiness in terms of credibility.

H14b: Cooperative norms positively influence the supplier's trustworthiness in terms of benevolence.

Organizational Strength and Economical/Financial Capacity (StCapacX). [19] consider the size, coverage, competences and personnel expertise, its physical, social and operational capital, and the cash in/cash out as base criteria for the evaluation of trust. The overall size of the supplier and its market share position indicate that many other businesses trust this supplier enough to do business with it [6]. Formally stated:

H15a: Organizational strength positively influences the supplier's trustworthiness in terms of credibility.

H15b: Economical/Financial capacity positively influences the supplier's trustworthiness in terms of credibility.

\section{$3 \quad$ Methodology and Results}

\subsection{Sample Definition and Data Collection}

In Management and Economics, empirical data is frequently used as a way to measure the validity of theoretical hypothesis. Therefore, to adequate the proposed model to reality, we conducted a questionnaire to determine which attributes are most important for the trustworthiness of the suppliers in a B2B relationship. The questionnaire was sent to 1126 firms in Portugal (from different industrial sectors), selected from the SABI (Iberian Balances Analysis System) firms database [37]. The number of obtained (and valid) responses was 127 (a 13\% response rate).

The questionnaire was composed of a set of questions (31 items) to help measure the importance of each one of the proposed determinants, based on a five-point Likert scale. Some of the questions were adapted from [3, 9, 14, 18]. Another question was also made, where the respondents were asked to select a set of terms that they considered most important for the business regarding the suppliers.

\subsection{Results}

In order to analyze the collected data in terms of descriptive statistics, IBM $®$ SPSS $®$ Statistics 20 was used. As a first analysis, the determinants that correspond to the items with a high response rate are shown in Table 1, column A. Column B represents the terms the respondents selected as the most important for the selection of their suppliers. As can be seen in Table 1, all the chosen terms (B) are part of the most scored determinants (A).

Exploratory Factor Analysis. As a first step for the hypothesis testing and determinants validation, an EFA was conducted. This is a traditional and the most 
Table 1. A - Determinants that correspond to $\sim 67 \%$ or more of the answers. B - Terms the respondents selected as the most important for the selection of their suppliers (response rate equal or superior to $50 \%$ ).

\begin{tabular}{llc|lc}
\hline \multicolumn{2}{c|}{$A$} & \multicolumn{2}{c}{$B$} \\
\hline & Determinant & Response rate, $\%$ & Determinant & Response rate, $\%$ \\
\hline 1 & Feedback & 97 & Delivery deadlines fulfillment & 92 \\
2 & Credibility & 95 & Honesty & 82 \\
3 & Benevolence & 95 & Cooperation & 82 \\
4 & Cooperation & 85 & Professionalism & 76 \\
5 & Accreditation & 84 & Quality control of end product & 70 \\
6 & Duration of buyer-supplier relationship & 80 & Promises fulfillment & 65 \\
7 & Past and experience & 75 & Compliance with ISO standards & 54 \\
8 & Quality & 64 & Accreditation & 52 \\
\hline
\end{tabular}

frequent kind of analysis [38], aiming to reduce the number of variables, where all the unobserved variables (attributes) can reflect in all the observed variables (items). Table 2 shows the rotation matrix obtained after the last run, resulting in 15 items (from the initial 31). As expected, the EFA showed the existence of a correlation between items from different determinants, as can be seen in Table 2. With this analysis, only five components ( $\mathrm{C} 1$ to $\mathrm{C} 5)$ could be extracted, two of which ( $\mathrm{C} 1$ and C2) did not correspond to the proposed attributes, i.e., the 15 proposed attributes, referred in section 2.1, were significantly reduced to five. This brought a new vision of the model and the need to define a name for the two new attributes. Table 3 shows the names proposed for the five components (based on the corresponding items in the matrix) and Figure 2 the new proposed model (based on the EFA carried out).

Confirmatory Factor Analysis. To confirm if the five components were responsible for the behavior of the 15 items, a CFA was conducted on the extracted items and components (using IBM $®$ SPSS $®$ Amos20). The model revealed a tolerable goodness of fit $\left(\mathrm{X}^{2} / \mathrm{df}=1.925 ; \mathrm{CFI}=0.901 ; \mathrm{GFI}=0.864 ; \mathrm{RMSEA}=0.086 ; \mathrm{P}[\mathrm{rmsea} \leq 0.05]<\right.$ 0.003 ), suggesting that the items provide a reasonable fit with the new proposed model (Figure 2). Therefore, the global score (based on the factor score weights ${ }^{4}$ calculated by Amos) for the Trustworthiness of the Supplier Agent $\left(\mathrm{T}_{\mathrm{AgS}}\right)$, for the analyzed sample, can be calculated according to the following expression:

$\mathrm{T}_{\mathrm{AgS}}=0.036 * \operatorname{Coop} 37+0.072 * \operatorname{Coop} 38+0.013 *$ Benev $42+0.008 * \mathrm{Fb} 31+0.006 * \operatorname{Coop} 32+$ $0.156 *$ Vincul $26+0.003 *$ Credi40 $+0.049 * \mathrm{Fb} 30+0.057 * \mathrm{Fb} 29+0.116 *$ Monit $22+0.061 *$ Monit $23+$ $0.196 *$ Vincul $28+0.069 *$ Inter7 + 0.022*Inter8 + 0.005*Dim1 1 .

The items that most contribute for $\mathrm{T}_{\mathrm{AgS}}$ are the items Vincul26, Monit22 and Vincul28. As can be seen in Figure 2, the amount of information (made) available (C1) has an extreme positive impact on the buyers' trust formation $(b=0.87, p<$ 0.003 ), largely supporting part of the initially proposed H12 (legal bonds) and H13 (feedback). The effect of professionalism and commitment (C2) on trust is insignificant, not supporting any of the proposed hypotheses, contrary to the expected. The international presence $(\mathrm{C} 3)$ has a significant positive impact on the buyer's trust

\footnotetext{
${ }^{4}$ Regression weights for predicting the unobserved variables from the observed variables.
} 
Table 2. Rotated component matrix obtained with the exploratory factor analysis

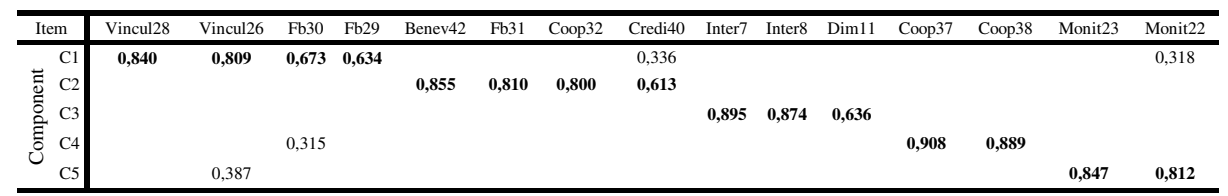

Table 3. The proposed new attributes to measure the trustworthiness of a supplier agent

\begin{tabular}{cl}
\hline Extracted Component & \multicolumn{1}{c}{ New Attribute } \\
\hline $\mathrm{C} 1$ & Amount of information (made) available \\
$\mathrm{C} 2$ & Professionalism and commitment \\
$\mathrm{C} 3$ & International presence \\
$\mathrm{C} 4$ & Cooperative norms \\
$\mathrm{C} 5$ & Audits (monitoring) \\
\hline
\end{tabular}

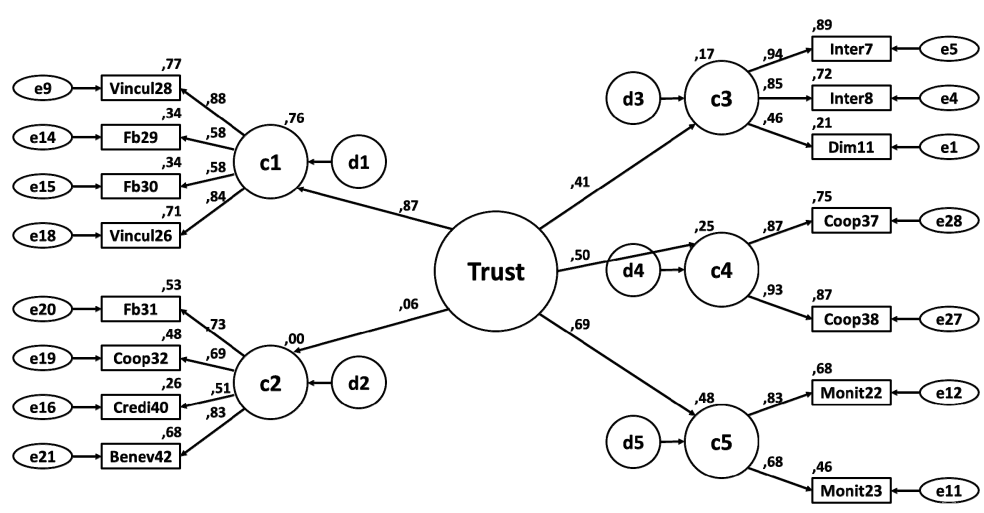

Fig. 2. The new proposed model for the determinants of the trustworthiness of a supplier agent, obtained after the exploratory factor analysis

formation, supporting H2. Similarly, the effect of cooperative norms (C4) on trust is significant, greatly supporting H14. Lastly, monitoring (or audits, C5) largely supports H10, having a positive influence on trust.

The implications of the obtained results are discussed in the following section.

\section{Conclusions and Future Work}

With the descriptive statistics analysis of the results, several trends could be derived from the responses, where the majority met the expectations. As a result, the most important attributes that are considered by the firms to determine the trustworthiness of a supplier are: feedback, deadlines fulfillment, cooperative norms, accreditation, buyer-supplier relationship duration (contrary to the results obtained by [6]), past and experience, and product's quality, supporting the hypothesis H13, H8, H14, H11, H5, $\mathrm{H} 1$ and $\mathrm{H} 7$, respectively. The two greater dimensions of trust, credibility and 
benevolence, are also supported. Thus, this would allow the modeling of a multiattribute supplier agent $\mathrm{AgS}_{\mathrm{x}}$ (corresponding to the referred supported hypothesis), which is of great relevance for making the ANTE platform more precise and realistic.

The EFA allied to the CFA slightly altered the results, leading to the extraction of only five attributes, two of them different from the originally proposed: amount of information (made) available (C1), professionalism and commitment (C2), international presence (C3), cooperative norms (C4) and monitoring (C5). In spite of the difference, they can be associated to the most important attributes supported by the descriptive statistic analysis and to some of the originally suggested: amount of information (made) available corresponds to the feedback and legal bonds; and professionalism and commitment corresponds to deadlines fulfillment, and also feedback (but these were not supported by the CFA). The international presence extracted attribute suggests that the presence of the supplier in different countries is important for the selection of the supplier. The existence of suppliers in several countries is a signal that they are requested for business by many buyers. The hypothesis $\mathrm{H} 12, \mathrm{H} 13, \mathrm{H} 2, \mathrm{H} 14$ and $\mathrm{H} 10$, respectively, were therefore supported by the CFA, also allowing the modeling of a multi-attribute supplier agent, $\mathrm{AgS}_{\mathrm{y}}$, but with less attributes than $\mathrm{AgS}_{\mathrm{x}}$. The $\mathrm{AgS}_{\mathrm{y}}$ attributes would therefore be: feedback, legal bonds, international presence, monitoring and cooperative norms, being only the feedback and cooperative norms common to the descriptive statistics supplier agent $\mathrm{AgS}_{\mathrm{x}}$.

As future work, and to try to validate the original proposed model directly using CFA, we are going to apply the same questionnaire to a larger sample (the 5000 most selling firms from the manufacturing industry and civil construction subsidized in Portugal) expecting a five-fold increase in the number of responses, and the possibility to better model a multi-attribute supplier agent on the system. It would also be interesting to conduct the questionnaire in other cultures.

As for the multi-agent ANTE platform, after finding the attributes to help model the trustworthiness of a supplier, it would be interesting if the user could model his buyer agent by choosing the weights he would give to each attribute, according to his preferences, in a Visual Analogue Scale (from 0 to 1).

Acknowledgments. We would like to thank the important comments of A. P. Rocha, H. L. Cardoso, J. Urbano and H. Martins. This work is financed by the ERDF European Regional Development Fund through the COMPETE Programme (operational programme for competitiveness) and by National Funds through the FCT - Fundação para a Ciência e a Tecnologia (Portuguese Foundation for Science and Technology) within project CRN / PTDC/EIA-EIA/104420/2008(FCOMP-01-0124FEDER-010120).

\section{References}

1. Cardoso, H.L., Urbano, J., Brandão, P., Rocha, A.P., Oliveira, E.: ANTE: Agreement Negotiation in Normative and Trust-Enabled Environments. In: Demazeau, Y., Müller, J.P., Rodríguez, J.M.C., Pérez, J.B., et al. (eds.) Advances on PAAMS. AISC, vol. 155, pp. 261-264. Springer, Heidelberg (2012) 
2. Urbano, J., Rocha, A.P., Oliveira, E.: A Dynamic Agents' Behavior Model for Computational Trust. In: Antunes, L., Pinto, H.S. (eds.) EPIA 2011. LNCS (LNAI), vol. 7026, pp. 536-550. Springer, Heidelberg (2011)

3. Pavlou, P.A.: Institution-based trust in interorganizational exchange relationships: the role of online B2B marketplaces on trust formation. Journal of Strategic Information Systems 11, 215-243 (2002)

4. Barney, J.B., Hansen, M.H.: Trustworthiness as a source of competitive advantage. Strategic Management Journal 15, 175-190 (1994)

5. Bromiley, P., Cummings, L.L.: Transaction Costs in Organizations with Trust. In: Bies, R., Sheppard, B., Lewicki, R. (eds.) Research on Negotiation in Organizations. JAI Press, Greenwich (1995)

6. Doney, P.M., Cannon, J.P.: An examination of the nature of trust in buyer-seller relationships. Journal of Marketing 61(1), 35-51 (1997)

7. Geyskens, I., Steenkamp, J.B., Kumar, N.: Generalizations about trust in marketing channel relationships using meta-analysis. International Journal in Marketing 15, 223-248 (1998)

8. Zaheer, A., McEvily, B., Perrone, V.: Does trust matter? Exploring the effects of interorganizational and interpersonal trust on performance. Organization Science 9(2), $141-159$ (1998)

9. Ganesan, S.: Determinants of long-term orientation in buyer-seller relationships. Journal of Marketing 58(1), 1-19 (1994)

10. Doney, P.M., Barry, J.M., Abratt, R.: Trust determinants and outcomes in global B2B services. European Journal of Marketing 41(9/10), 1096-1116 (2007)

11. Palmer, J.W., Bailey, J.P., Faraj, S.: The role of intermediaries in the development of trust on the www: the use and effectiveness of trusted third parties and privacy statements. Journal of Computer Mediated Communication 5(3) (2000) (online)

12. Castelfranchi, C., Falcone, R.: Trust theory - A Socio-Cognitive and Computational Model. Wiley, United Kingdom (2010)

13. Deutsch, M.: Trust and suspicion. Conflict Resolution 2(4), 265-279 (1958)

14. Sako, M., Helper, S.: Determinants of trust in supplier relations: evidence from the automotive industry in Japan and the United States. Journal of Economic Behavior and Organization 34, 387-417 (1998)

15. Ring, P.S., Van de Ven, A.H.: Structuring cooperative relationships between organizations. Strategic Management Journal 13, 483-498 (1992)

16. Mayer, R.C., Davis, J.H., Schoorman, F.D.: An integrative model of organizational trust. Academy of Management Review 20(3), 709-734 (1995)

17. McKnight, D.H., Chervany, N.L.: What trust means in e-commerce customer relationships: an interdisciplinary conceptual typology. International Journal of Electronic Commerce 6(2), 35-53 (2002)

18. Gounaris, S.P.: Trust and commitment influences on customer retention: insights from business-to-business services. Journal of Business Research 58, 126-140 (2005)

19. Msanjila, S.S., Afsarmanesh, H.: Assessment and Creation of Trust in VBEs. In: Camarinha-Matos, L., Afsarmanesh, H., Ollus, M. (eds.) Network-Centric Collaboration and Supporting Fireworks. IFIP, vol. 224, pp. 161-172. Springer, Boston (2006)

20. Elance Blog: How to review a provider profile (2009),

http://www.elance.com/p/blog/how_to_review_a_provider_ profile.html

${ }^{5}$ Elance is the world's leading platform for online employment that offers instant access to qualified professionals who work online. 
21. Zucker, L.: Production of trust: institutional sources of economic structure 1840-1920. Research in Organization Behavior 8(1), 53-111 (1986)

22. Elliott, R., Yannopoulou, N.: The nature of trust in brands: a psychosocial model. European Journal of Marketing 41(9/10), 988-998 (2007)

23. Ring, A., Schriber, M., Horton, R.L.: Some effects of perceived risk on consumer information processing. Journal of Academy of Marketing Science 8(3), 255-263 (1980)

24. Aaker, D.A.: Managing Brand Equity: Capitalizing on the Value of a Brand Name. Free Press, New York (1991)

25. Rauyruen, P., Miller, K.E.: Relationship quality as a predictor of B2B customer loyalty. Journal of Business Research 60, 21-31 (2007)

26. Chaudhuri, A., Holbrook, B.M.: The chain of effects from brand trust and brand affect to brand performance: The role of brand loyalty. Journal of Marketing 65(2), 81-93 (2001)

27. Aaker, D.A.: Building strong brands. Free Press, New York (1996)

28. Sabel, C.F.: Studied trust: building new forms of co-operation in a volatile economy. In: Pyke, F., Sengenberger, W. (eds.) Industrial Districts and Local Economic Regeneration. International Institute for Labour Studies, Geneva (1992)

29. Luhmann, N.: Trust and Power. Wiley, London (1979)

30. Gefen, D.: E-commerce: the role of familiarity and trust. OMEGA 28(6), 725-737 (2000)

31. Gulati, R.: Does familiarity breed trust? The implications of repeated ties for contractual choice in alliances. Academy of Management Journal 38(1), 85-112 (1995)

32. Williamson, O.E.: The economic institutions of capitalism. Free Press, New York (1985)

33. Ba, S., Pavlou, P.A.: Evidence of the effect of trust building technology in electronic markets: price premiums and buyer behavior. MIS Quarterly 26(3), 243-268 (2002)

34. Pavlou, P.A., Ba, S.: Does online reputation matter? An empirical investigation of reputation and trust in online auction markets. In: Proceedings of the 6th Americas Conference in Information Systems, Long Beach, CA, August 3-5 (2000)

35. Pavlou, P.A.: Trustworthiness as a source of competitive advantage in online auction markets. Best Paper Proceedings of the Academy of Management Conference, Denver, Colorado, pp. 9-14 (2002)

36. Axelrod, R.: The Evolution of Cooperation. Basic Books, New York (1984)

37. Dijk, B. v.: Bureau van Dijk Electronic Publishing, Company information in an instant. Nortel Networks, United Kingdom, Westacott Way (2003)

38. Marôco, J.: Análise de Equações Estruturais: Fundamentos teóricos, Software \& Aplicações. ReportNumber, Pêro Pinheiro (2010) 